\title{
Analysis of Sand Mining Areas in Lumajang Using WEBGIS
}

\author{
Usman Nurhasan \\ State Polytechnic of Malang \\ Malang, Indonesia \\ usman332119@gmail.com
}

\author{
Pramana Yoga Saputra \\ State Polytechnic of Malang \\ Malang, Indonesia \\ pramanay@gmail.com
}

\begin{abstract}
Mining process can also be described as the extraction of valuable minerals or other geological materials from the earth, usually from an orebody, lode, vein, seam, reef or placer deposit. These deposits form a mineralized package that is of economic interest to the miner. Mining is one of the sectors that triggering the rise of regional income. So, people have a great enthusiasm for it. In the mining industry, geographic information systems are useful as a tool for improving the efficiency associated with detailed study of a prospect area. Geographic information system is very helpful in the preparation of maps which is a combination of all information related to the prospect of the area being studied and developed. One form of geographic information system is WebGIS application. WebGIS applications are created using MapS erver technology and GeoLocation, which is processed in website engine. By using GeoLocation, can be presented information about the potential of the mining area either in the form of visual images or data. In this study, researchers wanted to develop a WebGIS application in order to obtain data about the geographical conditions of the sand mining area. The case study study is a sand mining area in Lumajang. From the WebGIS application, it is expected to provide accurate and up-to-date information about the potential of mineral resources in certain areas. $S o$, it can assist government in determining steps to make policy about mineral resource management.
\end{abstract}

Keywords- mining areas, Geographic information system, WEBGIS

\section{I.INTRODUCTION}

Spatial data management plays an important role in the management of Geographic Information System data (GIS). The process is done by applying relational elements of interconnected data. In its development, GIS not only serves to transform conventional maps into digital form, but this system has the ability to perform data analysis that refers to the human need for geographic information radically. The specific characteristic of GIS is the ability to perform statistical and overlay analysis called spatial analysis. This analysis is commonly used in digitized mapping because it is helpful in obtaining information from data processing. The term spatial analysis is very different from the analyst process of other information systems. In spatial analysis, no additional space / dimension is required. Geographic Information System has overlay analysis which is the process of data integration of different layers whereas in proximity analysis is a geographical analysis based on the distance between layers. Spatial analysis is done by overlaying two maps to then generate a new map of results as a result of the analysis. So that the processing of data passed in GIS can be done quickly.

In this case, data processing related to GIS can be done using various platforms, including through desktop platform, mobile device or website. There are significant differences between these three platforms, ie on the processing device used. Desktop-based devices are highly reliable in data processing, but less flexible when used for site mobilization and survey. While mobile devices have excellent mobilization access, but limited resources make this platform not maximal when used to process complex data. But for this case the web platform is the best platform. This is because web resources are highly qualified to perform complex data processes. Also in terms of mobility access, the web is just as good as a mobile platform [1].

Mining sites is an area that has extensive and unique characteristics. A problem survey in mining areas often encountered always takes time, effort and cost that does little for its completion. In addition it is one of the constraints on the extent of land mines is oversight of the mining area and its surroundings are often ineffective. The long-term effects of this problem are the emerging negative impacts of mining. An example is sand mining. A sand quarry mining with a fairly wide area. The mining process is done by taking the production of raw materials, namely sand that is usually formed from natural materials result of volcanic eruptions. Often the geographical location of the sand mining area is located along the curve of the river (meanders) and slopes of the mountains are far from human habitation. This condition is very profitable for the miners, because miners can freely exploit sand mining. Lack of supervision of the authorities as the extent of the mine site, further facilitate the emergence of illegal miners. Often miners do not pay attention to the longterm effects of the exploitation practiced primarily related to the stability of ecosystems and land management.

One solution to solve the above problems is to conduct strict supervision of the sand miners, both in terms of exploitation and in administrative permissions. GIS concepts can be applied to assist related offices in monitoring geographical conditions in the mining area. By utilizing WebGIS, the government can monitor the current state of geographical locations in the mine area and around the affected area of the mine. Results from WEBGIS processing can be used as a reference to issue a policy related to the mine. 


\section{THEORY REVIEWS}

\section{A. Geographic Information System (GIS)}

Geographic Information System is a process of data processing that produces spatialdata and non spatial data. In addition, the definition of GIS is a computer system used to capturing, storing, checking, integrating, manipulating, analyzing, and displaying data related to positions on the earth's surface [2]. In other words, GIS technology is used to assist decision makers in solving spatial problems by pointing to a variety of alternatives in the development and planning by modeling that produces a series of potential scenarios [3][4][5].

\section{B. Spasial Database}

Spatial Data Base describes a set of entities both have a fixed location or position or not fixed (it has a tendency to change, move, or grow). This spatial types have basic topographical properties that location, dimensions and form (shape).

Almost all SIGs have a mixture of types of spatial and non-spatial entities. Non-spatial types do not have a base location topographic property. Spatial database include soil texture, erosion, slope, elevation, soil type, place of extraction of material sourcing and deployment of settlements constructed voted in a vector Geographical Information Systems. Where the attributes are stored as relational databases that can be imported into the spatial model [6].

\section{Spasial Data and Type of Analysis}

Spatial data is data that points to the geographical position in which each characteristic has one location which must be determined in a unique way. It is also to determine the position of the absolute based on the coordinate system. For use in a small area, the simplest coordinate system is a regular rectangular grid. For use on larger areas, is based on commonly used cartographic projection [7]. The main characteristic from Geographic Information Systems is the ability to analyze systems such as statistical and overlay called spatial analysis. The analysis using Geographic Information System is unlike any other information system that is by adding the dimension of 'space' or geography. This combination illustrates the attributes in various phenomena such as the age of a person, the type of path, etc., which simultaneously relate to information that includes where one lives or the location of a path [8]. Analysis of GIS data can be done with many methods, including:

- Spatial Overlay

Spatial analysis is done by overlaying two maps which then produce a new map of analysis [7]. One of the basic ways to create or recognize spatial relationships through a spatial overlay process. Spatial overlays are done by performing a join operation and displaying together a set of data shared or shared in the same area. Combination results are a new set of data that identifies new spatial relationships.

\section{- Address Matching (Geo Coding)}

The street address is a common form of location information. Although its information still in the form of text containing the house number, the name of the street, the direction and the postcode. GIS requires a mechanism for transferring information in the form of this text to calculate geographic coordinates before an address can be displayed on a single map. Address matching (geocoding) is a process for merging one physical address of a location on earth with its logical address. To do so the SIG merges the addresses stored in the table file with its existing spatial data address. SIG then uses the coordinates of road features to calculate and mark the coordinates of a single address in a single file. The result is a new spatial data layer from a location point that describes the address of the file. Address matching is used to create ARC / INFO coverage.

- Buffer Analysis

Buffer analysis is used to identify areas around the features of geography. The process generates approximately circular buffer that there are features of geography and then identify or select features based on whether they are outside or inside the buffer limit.

- Map Overlay

It is a process of two thematic maps of the same area and overlaying one another to form a new map layer. The ability to integrate data from two sources using maps is key to Geographic Information Systems analysis functions.

- Map Overlay Concept

The Map Overlay address is a complementary interconnection between spatial features. Map Overlays combine spatial data and attribute data from two input themes. Three types of input features, via overlay which is a polygon:

1. Point-with-polygons, producing output in the form of dots

2. Line-with- polygon, producing output in the form of lines

3. 3. Polygons-with-polygons produce output in the form of polygons

\section{- Geoprocessing}

Pointing to the tools and processes used to generate the desired set of data. Geographic Information Systems include a large collection of tools that work with geographic information processes. This set of tools is used to operate GIS object information as a collection of data, attributes, and cartographic elements for map printing. Understanding commands given simultaneously in the form of data objects is the basis of the geoprocessing framework.

Data + Tools $=$ Data Baru

\section{WEBGIS}

GIS application development currently leads to webbased applications known as Webgis and mobile (GIS) platforms. This is because the applications development in the network environment has shown the potential in the desired online through the Internet network without knowing the boundary geograph ipenggunanya. In general, geographic information systems are developed based on the principles of 
input / data input, management, analysis and data representation.

Application for client that can communicate with Server as data provider through webprotocol known as HTTP (HyperText Transfer Protocol). To display and interact with GIS data a browser requires a plug-in or java applet and even both. The web server is responsible for the requesting process of the client and sends a response to the response. In the web architecture, a web server also regulates communication with server side GIS components.

To interact, communicate and obtain information needs to be designed for a Graphical User Interface

(GUI). PHP (HyperText Transfer Protocol) and VRML (Virtual Reality Modeling Language) users are an ideal GUI design for webgis applications. PHP became the most pupil language to create dynamic web at this time. VRML is introduced by a web consortium to generate interactive map views on the web. PHP can generate a lot of text information. In PHP, one of them becomes the controller of much of that information. The request is sent by VRML and then write the VRML node. The server communicates all PHP code when sending a response. So on the Line where the JSP code is displayed Server resends the Blank line to the browser. It is necessary to enter the PHP and VRML headers and the content type must change before the VRML header is specified. . In Figure1, The minimum architecture of a webgis system is shown

FIGURE 1. WEBGIS ARCHITECTURE

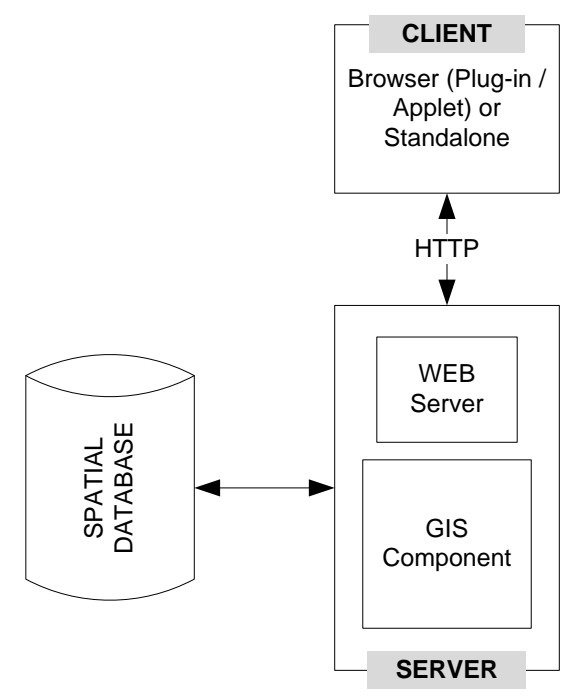

III. Methodology

\section{A. Case Study}

This research is focused on the area in Lumajang, precisely in Selok Awar-Awar region. The region is located at $113^{\circ} 9^{\prime} 4$ "BT-113 9 $^{\circ} 25^{\prime \prime}$ BT and 8 $8^{\circ} 16^{\prime} 03$ "LS-8 $16^{\prime} 90^{\prime \prime}$ LS. (Lumajang in number 2016) [2]is still a tropical region that can be interpreted as an area that lies between the isotherm line on equator line to the north or south. Selok Awar-Awar district from Lumajang is about $18 \mathrm{~km}$ with a time of 60 minutes by a motorcycle in normal speed. Selok Awar-Awar district has an area of $14.78 \mathrm{~km} 2$ within area of studied about 13 hectare to determine the impact of Sand Mining on agricultural land utilization in Selok Awar Awar, Pasirian Subdistrict, Lumajang. Based on data from Central Statistics Agency (BPS) the population of Lumajang Regency which is 9109 (nine thousand one hundred), which consists of 4,431 male population four thousand four hundred thirty one) and for female population proximately 4,678 (four thousand six hundred seventy eight). Regarding the policy from the local goverment in the form of sand mining policy that issued 61 permits for sand mining in Lumajang, issued by local government, however, 61 mining permits in Lumajang will be evaluated. The policy follows the discovery of illegal sand mining in the slopes of Mount Semeru and the southern coast of Java island. In 2015 there is still illegal sand mining that causes damage to rice farming that has an impact on the deterioration of environmental conditions and the decline in economic conditions and changing conditions social community of Selok Awar-Awar Village.

\section{B. SIG Work Procedure}

The GIS tool is a set of building blocks to combine many stages of operation. One tool performs an operation to the existing data to generate new data. The geoprocessing framework within the GIS is used to connect together a series of these operations. Working Procedure of the Geographic Information System

FIGURE 2. SIGWORK PROCEDURE

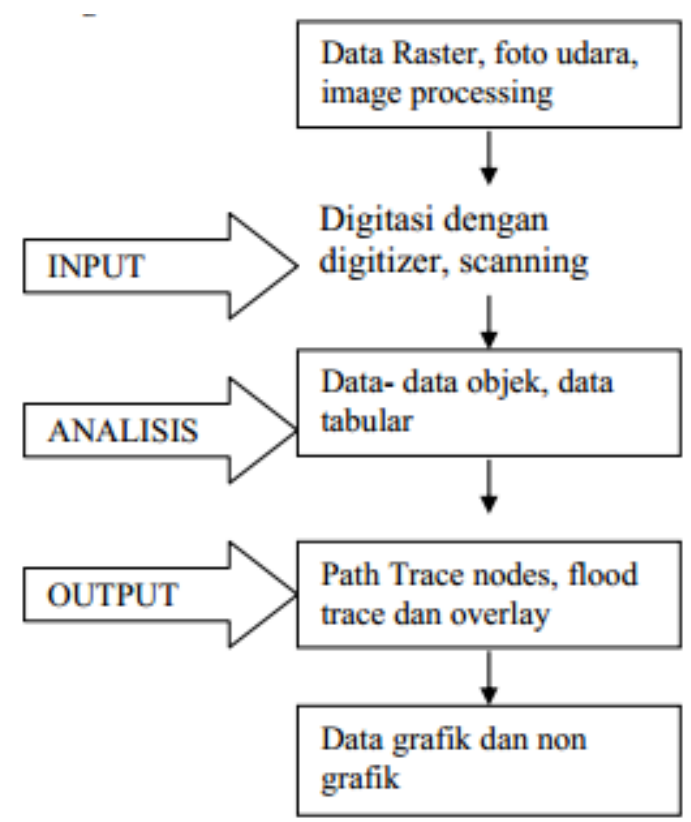

From Figure 2, obtained information that the procedure of GIS is not much different from other information systems it, what distinguishes the data type processed and generated. For more details, below is a brief description of the stages of GIS work procedures.

1. Spatial Data Input

Spatial data input is to create a map for its geographic data. If the map is made only through the usual estimates then the result of the digital map to be produced becomes invalid. Digitization process can be done by direct digitization using digitizer data input tool that can 
directly become digital map or by scanning cartographic map, aerial photography, or satellite which then done digitization process by import to software that can transform map result of scanning to map digital like Autocad or Autocad Map or MapInfo when using SIG ArcView device digitization process can be done directly in the worksheet and then converted to form the topology of spatial data formed with ArcInfo.

2. Spatial Data Analysis

The analysis here includes activities such as Overlay, making thematic maps and so on, where in general the activities of this analysis include:

1. Create buffers around points, lines and polygons.

2. Analyze the map with dots, lines and polygons and overlay it with slices, union, identity, delete, clip and paste operations..

3. Spatial Analysis by Buffer

By creating a buffer, a new area, polygon, or zone will cover (or surround) a spatial object (buffered object) in the form of point objects, lines or areas (certain polygons) with a certain distance.

\section{RESULTS AND ANALYSIS}

Data capture process by utilizing the existing layers in the Landsat imagery. The Landsat 8 OLI image is used as one of the remote sensing data used for a variety of global changerelated applications capable of depicting good terrain for land capability and spatial resolution appropriate for districtlevel coverage. Land capability mapping qualitative assessment as the basis for land use planning using geographic information systems and remote sensing used to support do planning appropriate land use based on land capability. By capturing multiple images which are then integrated into an image with high resolution using a basic image as the sample overlay. Some geographical circumstances are taken from the satellite is shown in Figure 3.

FIGURE 3. BASIC IMAGERY OF GEOGRAPHY CIRCUMSTANCE

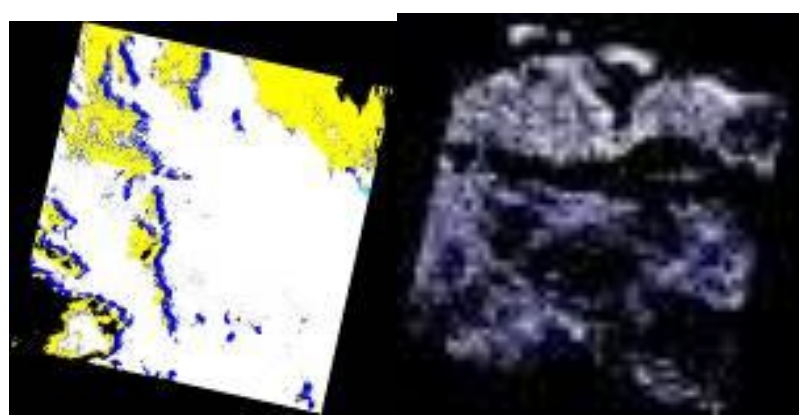

Both images above are the image of the geographical state of Selok Awar-Awar. By capturing some imagery as a complement of the layers to form an image with high resolution. Noise in each image, will be filtered to produce maximum image. Some supporting images are shown in Figure 4.
FIGURE 4. IMAGERY SUPPORT FOR LANSAT DATA

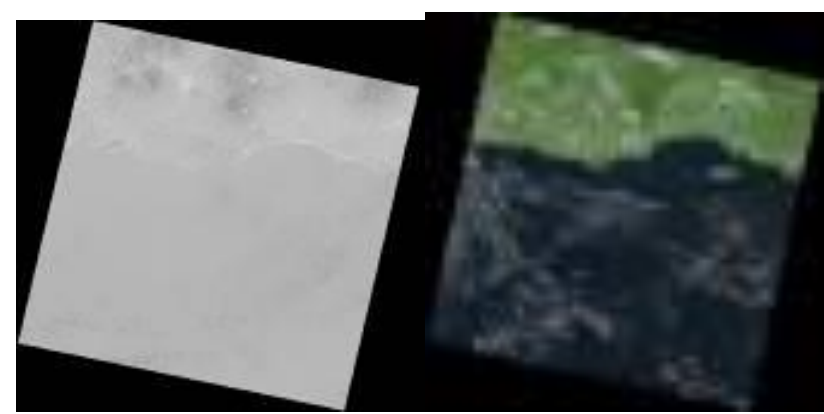

Primary data used in this research is Landsat 8 image with level 1T. Level 1T on Landsat 8 Image has been geometrically corrected using Ground Control Points (GCP) and Digital Elevation Model (DEM). Datum and UTM Zones used in Landsat 8 image are WGS 1984 and UTM Zone 50. The fusion technique that is done in this research is overlay fusion technique. Selection of this technique is done because it produces a good image visually and facilitate in doing visual interpretation of physical land. The next process is image enhancement (Image Enhancement). Image enhancement is done to further facilitate visual interpretation and understanding of an image. The advantage of digital images is that it allows us to manipulate the pixel values of an image. Although the image has been corrected against the radiometric, atmospheric and sensor effects before image data is distributed to the users, the appearance of the image is still less optimal for visual interpretation..

From the case study of the area taken, the geographical location of the Sand Mining in AwarAwar, is a curve of the river that originates from the foot of Mount Semeru and its estuary on the south coast. It is clear that the area is rich in iron sand. This is shown by the black color in the image, more dense than the color of the soil.

Sand mining in Selok Awar Awar, Lumajang is generally illegal mining although sand mining around the coast has been officially banned, but is done by the people who want to utilize natural resources in order to improve the quality and comfort of quality of life they keep doing illegal sand mining. Economic activities to supplement the better income would have a negative impact for the community and farmers in Selok Awar-Awar. Within one year alone in the coastal area there was a large pit hole caused by continuous sand mining. This is seen from the landsat image shown in Figure 5. In the image that has been processed using the overlay method, seen some river fault. The fault was caused by the massive exploitation of sand mining without regard to the rules of land governance.

The impact of sand mining activities in the river basin in Lumajang has a negative impact on the existence of the environment, where the sand mining causes a balance of natural conditions that cause environmental damage. Based on the results of the research conducted there are several negative impacts associated with sand mining activities in the river flow in Lumajang district, especially in Selok Awar-awar. These impacts include:

1. Landslides or soil erosion.

Mining activities carried out in watersheds in Lumajang Regency can affect the physical, chemical and 
biological properties of the soil through stripping of topsoil, mining, washing and tailings disposal. Mining people who do not pay attention to environmental aspects will cause threatened areas around with the dangers of erosion and landslides due to loss of cover vegetation.

Land used for mining is not entirely used for mining operations simultaneously, but gradually.

FIGURE 5. LANDSAT IMAGERY ZOOM IN SELOK AWAR-AWAR

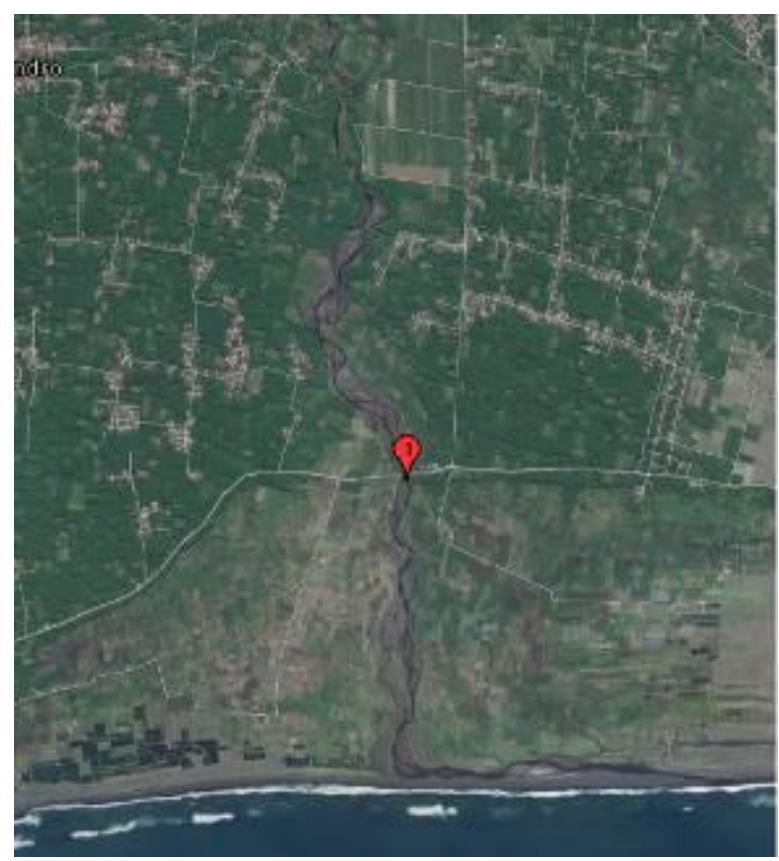

2. There is damage on the shoreline which is a tourism spot, Watu Pecak beach with there are large holes caused by sand mining is done continuously and excessively

3. Agricultural land damaged by the entry of sea water by bringing sand material into agricultural land that resulted in flooding and damage the condition of paddy rice field land that is detrimental from the farmers.

4. Other damages in the environment around sand mining in the Selok Awar Awar neighborhood is damaged and its perforated access road due to the activities of large vehicles in and out transporting sand, as well as noise pollution due to traffic from large vehicles, as well as dust from sand being transported and smoke from vehicles carrying sand interfere with the local residents..

5. The decrease of farmers' income and the loss of livelihoods due to the land they are destroying due to the sand mining.

6. Reduced the land as much as 10 hectares of initial land area before the impact of mining is 28 hectares to 18 hectares because it cannot be repaired as a result of sand mining activities.

7. The emergence of social conflicts between farming communities with the sand mining that led to the murder of Mr. Kancil and Persecution Mr. Tosan.

From some of the negative impacts of sand mining mentioned, the researchers concluded that sand mining in
Selok Awar-Awar is detrimental and has a direct impact on agricultural land, ie damage to agricultural land that causes a decline in the economic condition of the community that triggers the decline in income and its loss farmers' livelihoods. In addition, it also raises social disparities among farmers that trigger the emergence of social conflict in the community between farmers and sand miners.

Negative impacts can be reduced by many things, including with the establishment of good cooperation between relevant agencies and supported by public awareness. The government can take advantage of various ways to monitor mineral and mineral-rich locations, one of them by utilizing IT-based technology. One of them is remote sensing using mobile base.

\section{CONCLUSION}

\section{A. Conclusion}

Based on the texture analysis the landsat data can be easily used to recognize the location of the sand mining visually (texture is smoother compared to other vegetation). In addition, object analysis using Landsat imagery is not only able to use one polarization or 2 polarization, but must use two or more polarization. Overlay method can combine existing polarization so that spatial data can be analyzed well.

Based on the comparison of image classification results indicate that the landsat image cannot display visual altitude well, but only in the form of topographic map. Despite all the advantages and disadvantages of Landsat imagery, remote sensing satellite technology offers considerable advantages in mine site studies and has become a useful tool for monitoring ecosystem changes and land-use functions. The output of Landsat imagery analysis can be used as basic information in planning and policy conservation. To ensure the accuracy of the analysis, important factors such as spectral and spatial resolution and image classification techniques should be a key consideration.

\section{B. Suggestion}

The improvement that must be done in order to get more accurate result is, need to do direct field survey. This survey aims to determine the conditions of the sand mines especially related licensing. By comparing data from landsat and survey images directly, it is expected that the output validity will be objective.

\section{REFERENCES}

[1] Pressman, R.S. (2010), Software Engineering : A Practitioner's Approach, McGraw-Hill, New York, 68

[2] Rice. 2000. GIS/Data Center: GIS Links, http://riceinfo.rice.edu/Fondren/GDC/gislinks.shtml

[3] Miller, L. 1993. Charles Eliot, preservationist, park planner, and landscape architect. Department of Landscape Architecture, State College, Pennsylvania State University, Pennsylvania

[4] Feick, Robert D. and Hall, G. Brent. 1999. Consensus-building in a Multiparticipant Spatial Decision Support System, URISA Journal, Volume 11, Number 2, Pages $17-23$

[5] Keenan, P. 1997. 'Using a GIS as a DSS Generator'. Department of Management Information System, University College Dublin, Working Paper MIS 95-9

[6] Prahasta, E. 2001. Konsep-konsep Dasar Sistem Informasi Geografis, Penerbit Informatika, Bandung 
[7] Tuman. 2001. Overview of GIS,

http://www.gisdevelopment.net/tut orials/tuman006.htm

[8] Keele. 1997. An Introduction to GIS using ArcView : Tut orial, Issue 1, Spring 1997 based on Arcview release 3, http://www.keele.ac.uk/depts/cc/helpdesk/arcview/av_prfc.htm 